\title{
Review: Biological determinants of between-animal variation in feed efficiency of growing beef cattle
}

\author{
G. Cantalapiedra-Hijar ${ }^{1 \dagger}$, M. Abo-Ismail ${ }^{2}$, G. E. Carstens ${ }^{3}$, L. L. Guan², R. Hegarty ${ }^{4}$,

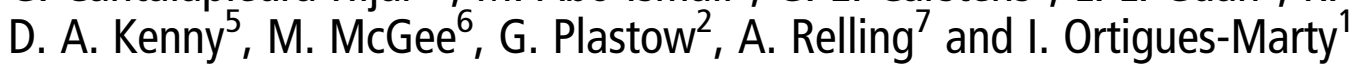 \\ ${ }^{1}$ Université Clermont Auvergne, INRA, VetAgro Sup, UMR Herbivores, F-63122 Saint-Genès-Champanelle, France; ${ }^{2}$ Department of Agricultural, Food and Nutritional \\ Science, University of Alberta, Edmonton, AB, Canada T6G 2P5; ${ }^{3}$ Department of Animal Science, Texas A\&M University, College Station, TX 77843, USA; ${ }^{4}$ University \\ of New England, Armidale, NSW 2350, Australia; ${ }^{5}$ Animal and Bioscience Research Department, Animal \& Grassland Research and Innovation Centre, Teagasc, \\ Grange, Dunsany, Co. Meath, C15 PW93, Ireland; ' ${ }^{6}$ Livestock Systems Research Department, Animal \& Grassland Research and Innovation Centre, Teagasc, Grange, \\ Dunsany, Co. Meath, C15 PW93, Ireland; ' Department of Animal Sciences, The Ohio State University, 1680 Madison Ave., Wooster, OH 44691, USA
}

(Received 2 February 2018; Accepted 3 May 2018; First published online 24 August 2018)

Animal's feed efficiency in growing cattle (i.e. the animal ability to reach a market or adult BW with the least amount of feed intake), is a key factor in the beef cattle industry. Feeding systems have made huge progress to understand dietary factors influencing the average animal feed efficiency. However, there exists a considerable amount of animal-to-animal variation around the average feed efficiency observed in beef cattle reared in similar conditions, which is still far from being understood. This review aims to identify biological determinants and molecular pathways involved in the between-animal variation in feed efficiency with particular reference to growing beef cattle phenotyped for residual feed intake (RFI). Moreover, the review attempts to distinguish true potential determinants from those revealed through simple associations or indirectly linked to RFI through their association with feed intake. Most representative and studied biological processes which seem to be connected to feed efficiency were reviewed, such as feeding behaviour, digestion and methane production, rumen microbiome structure and functioning, energy metabolism at the whole body and cellular levels, protein turnover, hormone regulation and body composition. In addition, an overall molecular network analysis was conducted for unravelling networks and their linked functions involved in between-animal variation in feed efficiency. The results from this review suggest that feeding and digestive-related mechanisms could be associated with RFI mainly because they co-vary with feed intake. Although much more research is warranted, especially with high-forage diets, the role of feeding and digestive related mechanisms as true determinants of animal variability in feed efficiency could be minor. Concerning the metabolic-related mechanisms, despite the scarcity of studies using reference methods it seems that feed efficient animals have a significantly lower energy metabolic rate independent of the associated intake reduction. This lower heat production in feed efficient animals may result from a decreased protein turnover and a higher efficiency of ATP production in mitochondria, both mechanisms also identified in the molecular network analysis. In contrast, hormones and body composition could not be conclusively related to animal-to-animal variation in feed efficiency. The analysis of potential biological networks underlying RFI variations highlighted other significant pathways such as lipid metabolism and immunity and stress response. Finally, emerging knowledge suggests that metabolic functions underlying genetic variation in feed efficiency could be associated with other important traits in animal production. This emphasizes the relevance of understanding the biological basis of relevant animal traits to better define future balanced breeding programmes.

Keywords: residual feed intake, ruminant, feed conversion ratio, steer, individual variability

\section{Implications}

Why comparable animals reared in similar conditions have such different abilities to transform feed into food (i.e. animal feed efficiency) is a current relevant question for the beef industry. This review suggests that feeding and digestive-

\footnotetext{
${ }^{\dagger}$ E-mail: gonzalo.cantalapiedra@inra.fr
}

related factors are associated to animal variation in feed efficiency mainly because they co-vary with dry matter (DM) intake and that metabolic energy-consuming processes could be the true determinants. Finally, as some mechanisms related to feed efficiency could interact with other important animal traits, the information analysed and discussed in this review could help to better define future multi-trait breeding programmes. 


\section{Introduction}

Ruminants can transform human-inedible feed (e.g. grasses, forages and by-products rich in cellulose) into high-quality human-edible food (e.g. meat, milk). However, this unique advantage of ruminants entails a low conversion efficiency, especially in growing cattle, compared with other livestock species and is associated with $\mathrm{N}$ pollution and greenhouse gas emissions. Given the growing human demand for animal protein-food, the scarcity of natural resources and the need to preserve our environment, improving the conversion of feed resources into animal products (i.e. animal feed efficiency) is becoming a greater challenge. Huge progress has been made to understand dietary factors influencing mean animal feed efficiency (e.g. feed conversion efficiency of a whole group), but there exists a considerable amount of animal-to-animal variation (phenotypic and genotypic) around this mean which remains to be fully understood.

Animal feed efficiency is a complex and multi-trait phenotype. Two different metrics, likely reflecting different underlying mechanisms, are currently used as measures of feed efficiency in growing beef cattle. First, the ratio between the amount of feed consumed and the animal weight gain, termed feed conversion ratio (FCR), was traditionally commonly used by the beef industry. However, despite the fact that FCR is a useful index to evaluate management practices on production efficiency, today it is a questionable trait for genetic selection because of its strong negative correlation with BW gain and thus, its undesirable effect on mature body size (and consequently on feed costs) of the breeding herd. In addition, selection based on ratio traits, such as FCR, may result in divergent and unpredictable response in the component traits (Zetouni et al., 2017) leading, for instance, to inconsistent relationships (Arthur and Herd, 2012) with feed intake (trait in the numerator). The second metric is the difference between actual feed intake and expected feed requirements for maintenance and weight gain, the main energy sinks in growing animals, termed residual feed intake (RFI). Animals with lower RFI are deemed to be more efficient since they eat less than expected. Residual feed intake has gained popularity in recent years, mainly among geneticists, because of its lack of phenotypic correlation with BW gain and animal size. Being a measure of feed efficiency that is independent of an animal's performance has led to the belief that variation in RFI may represent inherent variation in basic metabolic processes that determine production efficiency (Archer et al., 1999). However, in general RFI has been poorly accepted by industry mainly because animals ranked as superior in terms of RFI may be growing slowly (Berry and Crowley, 2013).

The biological determinants of animal-to-animal variation in feed efficiency are still far from being fully understood. However, they need to be comprehended for several reasons (Richardson et al., 2004): (i) it may provide insights into the undesirable side effects of selection for feed efficiency on other important animal traits such as robustness, reproduction and health (Rauw et al., 1998) and thus help us to better design balanced breeding programmes; (ii) it may reveal novel management strategies aiming to improve the performance of feed inefficient animals and better matching diet formulation to individual animal requirements; and (iii) it may result in the discovery of cheap and rapid methods (biomarkers) for ranking individuals for genetic and management purposes without the need for feed intake measurement. The study of biological mechanisms underlying the animal-to-animal variation in feed efficiency has intensified over the past 15 years. Most of these studies aimed to identify the determinants and molecular bases explaining why comparable animals reared in similar conditions differ in feed efficiency, with some studies targeting the discovery of biomarkers to predict this phenotype. Although some excellent reviews are published in relation to the biological basis of feed efficiency in beef cattle (Richardson and Herd, 2004; Herd and Arthur, 2009) extensive new data have emerged especially regarding the molecular basis of feed efficiency. The aim of this paper is to review the recent scientific literature on the biological determinants and the molecular basis of feed efficiency, with particular reference to growing beef cattle phenotyped for RFI. Previous research indicates that no single mechanism is responsible for determining animal feed efficiency (Herd et al., 2004). Furthermore, many observed differences between animals divergent in feed efficiency may be a direct consequence of a difference in intake. Therefore, this review also attempts to identify which set of plausible mechanisms might be causing variation in animal feed efficiency directly as opposed to traits whose change is simply a consequence of lower intake.

\section{Feeding behaviour and physical activity}

Feed intake is a function of meal size and frequency and is regulated by a combination of physical and metabolic mechanisms, with the relative importance of these two processes dependent on prevailing dietary characteristics (Fitzsimons et al., 2017). Feeding behaviour is determined by the integration of central and peripheral signals in brain feeding centres (Allen, 2014).

Considering the substantial phenotypic differences observed in DM intake between efficient and inefficient beef cattle (Kelly et al., 2010; Fitzsimons et al., 2013 and 2014), feeding behaviour likely makes an important contribution to the underlying variation in feed efficiency of beef cattle (Kelly et al., 2010; Fitzsimons et al., 2017). Nevertheless, activity associated with consumption, particularly for forage diets, is a significant energy sink in cattle (Fitzsimons et al., 2017). Key feeding behaviour activities include frequency and duration of individual feeding events - collectively, termed daily feeding duration ( $\min$ or $\mathrm{h}$ ) - and eating rate $(\mathrm{g} / \mathrm{min})$. To quantify the effect of RFI status on daily feeding duration, Kenny et al. (2018) conducted a meta-analysis of nine published studies with growing beef cattle offered energy-dense high-concentrate diets and found that high-RFI cattle spent proportionately 0.12 more time eating than their 
low-RFI contemporaries. The 0.17 proportionately higher DM intake of the high-RFI animals in that analysis implies that they also had a faster eating rate than the low-RFI animals. Published research evaluating the association between RFI status and daily feeding events is equivocal, and may be partly due to the diversity of diet types offered (Kenny et al., 2018). Physical activity is a non-productive function contributing to energy use in cattle and is interconnected with feeding-related activity behaviour, especially under grazing conditions. There is evidence that the occurrence of nonfeeding events, where cattle are at the feed face but do not consume any feed, is less in low- compared with high-RFI beef cattle (Kelly et al., 2010). The comparatively few studies published evaluating non-feed related activities - time spent standing, lying or active - in beef cattle varying in RFI status (Lawrence et al., 2012), have shown inconsistent behavioural effects between divergent RFI phenotypes under confined and/or grazing conditions (Kenny et al., 2018).

Most of the aforementioned research involved cattle in confinement, usually offered energy-dense diets, where individual animal intake and associated behaviour was relatively easily determined using automated feeding systems coupled with electronic animal identification sensors. In contrast, there is comparatively little published information pertaining to feed efficiency in grazing beef cattle despite the fact that the majority of beef production systems worldwide are largely based on pasture (Lawrence et al., 2012; Manafiazar et al., 2015; Oliveira et al., 2016). This is not surprising considering how challenging it is to accurately obtain equivalent measurements with individual animals grazing pasture (Lawrence et al., 2012).

However, in this context, there is evidence of genotype-byenvironment interactions for RFI in growing beef cattle (Kenny et al., 2018). For example, beef heifers previously ranked as divergent for RFI when offered grass silage plus supplementary concentrates whilst indoors did not differ in herbage intake when subsequently grazing pasture (Lawrence et al., 2012). Similar findings were obtained by Oliveira et al. (2016). In contrast, Manafiazar et al. (2015) reported that RFI measured under drylot conditions was positively correlated $(r=0.30)$ to RFI measured under grazing conditions. Discrepancies between grazing-based studies may be due to the very low precision of methods used to estimate pasture intake (Lawrence et al., 2012). To overcome this particular limitation and facilitate more accurate collection of grass herbage intake data, recent studies have used a zerograzing regime instead (Coyle et al., 2016 and 2017). Research evaluating the within-animal repeatability of intake, growth and feed efficiency between two consecutive feeding periods in beef cattle offered grass silage followed by zero-grazed fresh grass (Coyle et al., 2016), or zero-grazed grass followed by a high-concentrate diet (Coyle et al., 2017), concluded that DM intake, and to a lesser extent RFI, were somewhat repeatable traits, whereas FCR and average daily live weight gain were not. This implies that there is a reranking in feed efficiency in beef cattle offered fresh grass herbage compared to other diets, especially for the measure
FCR. With cattle offered grass herbage, ruminal distension is more likely to dominate control of feed intake rather than fuel-sensing by tissues when fuel supply is in excess of that required, such as occurs on high-energy concentrate-based diets (Allen, 2014); thus, a strong relationship between ruminal fill and grazing dynamics is evident (Gregorini et al., 2008). Furthermore, under grazing conditions ingestivedigestive behaviours become significant due to variation in herbage nutrient supply and composition, and also differential energy expenditures associated with the harvesting and defoliation process (Gregorini et al., 2008). Genotypeby-environment interactions are particularly important if estimates of genetic merit for feed efficiency are derived under feeding and management systems that are different from commercial farm conditions.

Collectively, these results indicate that in confinement feeding, differences in feeding behaviour-related traits between low- and high-RFI cattle are largely a reflection of differences in intake; however, under grazing conditions the relative contribution of these traits to between-animal variation in feed efficiency is unknown. Much more research is required on feed efficiency of beef cattle grazing pasture, but precision in methodologies used to estimate grass herbage intake need to be improved upon in order to discern realistic differences in consumption between individual animals.

\section{Digestibility and methane emission}

Digestibility and methane emissions markedly limit the efficiency of capture of dietary energy in useful animal products. Since methane production ( $\mathrm{g} \mathrm{CH}_{4} /$ day) is linearly related to DM intake, selection of cattle for low-RFI may substantially reduce methane production without reducing the growth of the animal (Basarab et al., 2013). Lower methane production is not always seen in animals of lower RFI, however, because (1) divergent RFI cattle do not always exhibit differences in DM intake when digestibility is measured outside the RFI test period (Jones et al., 2011) and (2) low RFI cattle often exhibit up to a $4 \%$ points increase in whole tract DM digestibility, increasing the quantity of substrate available for fermentation and methanogenesis per unit feed (Bonilha et al., 2017). Richardson and Herd (2004) concluded that the processes of digestion were responsible for at least $10 \%$ of variance in RFI. However, when available literature studies reporting concurrent feed intake and digestibility data in divergent RFI cattle were evaluated through meta-analysis, a negative correlation between DM digestibility and DM intake was found on average (Figure 1): the slope representing the assumed loss in digestibility as the DM intake increases (Sauvant and Nozière, 2016). This result suggests that overall higher DM digestibility in low RFI cattle might be mostly the consequence of lower DM intake and likely not the opposite.

Ideally, it is not just a lower methane production resulting from selection of low RFI cattle that should be targeted to increase efficiency of energy capture by the animal, but also a reduced methane yield (MY; $\mathrm{g} \mathrm{CH}_{4} / \mathrm{kg} \mathrm{DM}$ intake). Beef 


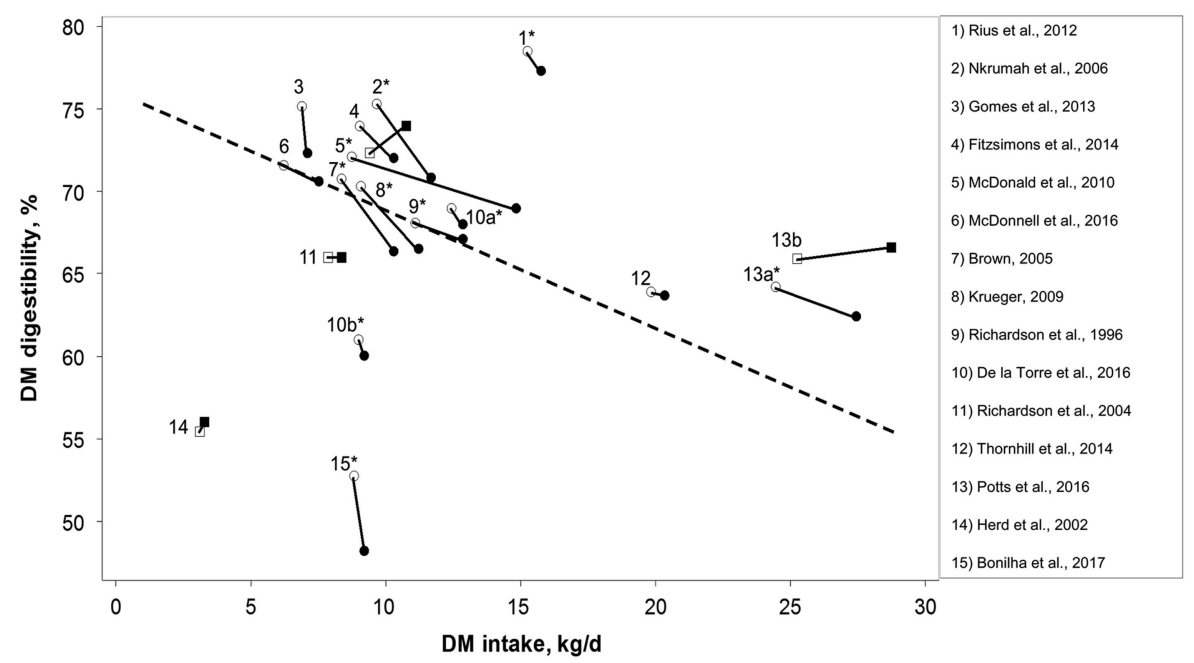

Figure 1 Relationship between dry matter (DM) digestibility and DM intake in extreme residual feed intake (RFI) cattle from published data. Empty symbols refers to negative RFI animals, whereas full ones refer to positive RFI animals within the same study. A star beside the number means that significant differences $(P<0.10)$ in digestibility between divergent RFI animals were originally reported in that particular study. Overall, a significant negative relationship was found between DM digestibility and DM intake once corrected for the effect of the study (dashed thick line: DM digestibility $=76.0 \pm 1.79-0.72 \pm 0.15 \times \mathrm{DM}$ intake; $\mathrm{RSE}=1.13 ; r^{2}=0.97$ ). Four out of 17 studies did not show negative relationship between DM digestibility and DM intake across divergent RFI animals (square symbols). References are listed at the end of the Supplementary Materials.

cattle divergent for RFI have not shown consistent differences in MY, and there is no obvious physiological reason why low RFI animals even if exhibiting reduced methane production, should also have a reduced MY. On the contrary, reducing an animal's level of intake (relative to maintenance) often increases MY, as recently observed in extreme RFI beef cattle (Herd et al., 2016). While reducing feeding level generally increases mean retention time of digesta in the rumen (Sauvant and Nozière, 2016), the limited data available for animals divergent in RFI fails to show longer mean retention time in animals of lower RFI, perhaps because of smaller rumens that are also associated with low RFI animals (Fitzsimons et al., 2014). Smaller rumen liquid volumes and a shorter mean retention time have been found in low RFI dairy cows (Rius et al., 2012) and in low MY sheep (Goopy et al., 2014). Differential responses in rumen volume and digesta retention time with divergence in RFI may account for some of the variability in effects of RFI on MY.

There is, however, evidence of genetically controlled between-animal variation in MY, giving scope for selection for reduced MY to improve efficiency of capture of energy consumed by the animal. Within a herd, there are cattle which display both low RFI and low MY (Figure 2). Selection pressure could be applied to MY in addition to selection for $\mathrm{RFI}$, to provide downward pressure on both DM intake and MY. There remains the challenge of measuring methane production on a commercial scale and more data are required to confirm genetic relationships. Genetic variation in MY among cattle has recently been quantified (Donoghue et al., 2016) and, like RFI, can be selected against without impacting animal productivity, as no adverse genetic correlations with production traits are apparent. Interestingly, when comparisons were conducted in steers divergent in residual gain (gain adjusted to intake and BW), to overcome the problem associated with the inherent correlation

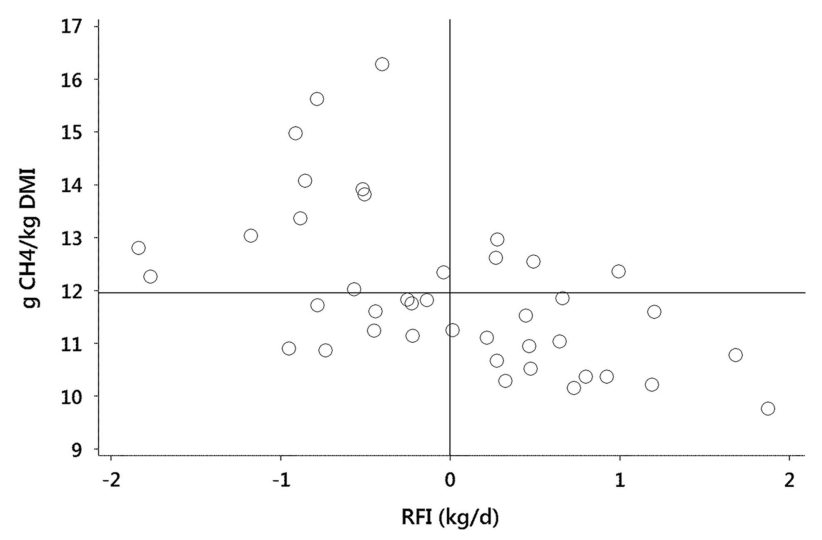

Figure 2 Distribution of methane yield $\left(\mathrm{g} \mathrm{CH}_{4} / \mathrm{kg}\right.$ dry matter intake (DMI)) and residual feed intake (RFI) among 41 Angus cattle on a feedlot ration with methane measured by Greenfeed Emission Monitors. Data show some cattle exhibit both RFI and methane yield that are below the group means (displayed as solid lines). Data are raw values from Herd et al. (2016).

between methane production and DM intake, no differences in daily methane production were noted (Freetly et al., 2015). This finding may indicate that methane emissions are not always a contributor to animal-to-animal variation in feed efficiency.

One objection to selecting on MY, like selecting for FCR, is the unpredictable consequences of selecting on a ratio trait (Zetouni et al., 2017), where response could be due to changes in the numerator, denominator or both. For this reason, the approach to selection has moved to residual methane (Herd et al., 2014), with residual methane (methane production of the individual compared with its predicted emission) being strongly correlated with MY ( $r=0.82$ to 0.95 ) but independent of DM intake and only weakly correlated with production traits. 
In summary, the above considerations identify betweenanimal variation that exists in a number of genetically controlled traits and can be selected to reduce emission of the enteric greenhouse gas, methane. Effects of selection for RFI on MY are less certain but selection for residual methane $\left(h^{2}=0.19\right.$; Donoghue et al., 2015) as a complementary trait to RFI offers a new means of reducing MY. Together, RFI and residual methane offer a significant opportunity to reduce the emission intensity (methane produced per unit of beef) whether considered on an individual animal or a whole enterprise basis. Despite a paucity of data, a trade-off between digestion and methane emissions might exist when improving animal feed efficiency, meaning that the positive impact for the animal of increasing digestibility could entail a higher MY and vice versa.

\section{Rumen microbiota}

The relationship between rumen digestion and feed efficiency has been investigated and there is emerging evidence of individualized variation in microbiome within a cattle population when animals are fed the same diet and raised in the same environment (Jami and Mizrahi, 2012). Guan et al. (2008) first proposed the linkage between the rumen microbiota (and its metabolites) and animal-to-animal variation in feed efficiency. Since then many efforts have been made worldwide further supporting that, although minor, there exist changes in the rumen microbiome associated with animal-to-animal variation in feed efficiency (Supplementary Table S1). For example, in beef steers, bacterial phylotypes (Succinivibrio sp., Eubacterium sp., and Robinsoniella sp.) were identified to be potentially associated with RFI (study\#5; Supplementary Table S1), however, such a relationship is diet dependent. Succinivibrio bacteria, higher in high efficient animals (Study\#4 (low FCR) and \#5 (low RFI under a low-energy diet)), have been suggested to utilize hydrogen for the production of succinate, therefore lowering its availability for methanogenesis (Pope et al., 2011). Similarly, studies\# 2, 3 and 6 (Supplementary Table S1) reported a less diverse methanogen community in efficient cattle (low RFI) with lower abundance of specific methanogenic species in less efficient animals (high RFI). For example, lower abundance of Methanobrevibacter sp. strain AbM4 and Methanosphaera stadtmanae (which synthesize methane through a non- $\mathrm{CO}_{2}$-based pathway) were found in the rumen of efficient animals (Study\#2; Supplementary Table S1). These methanogens are known to consume substrates such as acetate, and limit their availability to the host. Recent metagenomics and metatranscriptomics based in-depth assessment of the rumen microbiome in beef (Study\#14) and dairy (Study\#11) cattle fed high-energy concentrate diets also suggest that the rumen microbiome is less genetically diverse and active in efficient cattle than inefficient ones. Both studies indicated that microbial nitrogen metabolism rather than carbohydrate metabolism is more related to variations in cattle feed efficiency (RFI and FCR). Although these findings contradict the prevailing dogma that greater diversity is always better, they shed light on the rumen microbiome and how their functional potential (genes) and activities (messenger RNAs (mRNAs)) can contribute to host feed efficiency. The less diverse microbial activity in efficient animals may reflect a simpler rumen microbiome, which uses less substrate and energy for microbial proliferation and directs more nutrients to the host. This suggests that intervention strategies to inhibit the 'unnecessary rumen microbial activity' (the enriched functions in inefficient animals) may lead to the improvement of feed efficiency. However, more studies are warranted to confirm that lowering microbial diversity does not impact resilience and health status.

From studies reported in Supplementary Table S1, it is evident that the overall microbial profiles do not differ across divergent feed efficiency phenotypes: all individuals under the same feeding condition have a 'core' bacterial structure and most dominant bacteria are not relevant for this trait (Hernandez-Sanabria et al., 2010). However, the association of specific microbial phylotypes (bacteria and archaea) to RFI (Supplementary Table S1) may support the concept of a specific and individualized microbiome contributing to the animal variation in feed efficiency. This raises the question about what may drive such individualization and how such knowledge could be applied to the beef industry. A recent survey of the rumen microbiota of 732 beef cattle with genotypes by $50 \mathrm{~K}$ bovine single nucleotide polymorphism panels (Li et al., unpublished data) by University of Alberta team, further showcased that $\sim 30 \%$ of the rumen microbial taxa are potentially heritable $\left(h^{2} \approx 0.15\right)$, especially the members belonging to Firmicutes phylum, which play very important roles in fibre digestion and carbohydrate metabolism. In contrast, the taxa belonging to Bacteroidetes had a low heritability, in accordance with abundance shift when diet changes. Moreover, the same research group identified 19 single nucleotide polymorphisms located on 12 bovine chromosomes and associated with 14 rumen microbial taxa, and some of these rumen microbiota-associated single nucleotide polymorphisms were known as quantitative trait loci for feed efficiency in cattle (Li, 2017). These findings suggest that it may be possible to identify host genetic components that influence the rumen microbiome which can be used for future breeding strategies to improve rumen function and feed efficiency. Some speculations are that some traits differing across RFI groups, such as the size of the rumen (Fitzsimons et al., 2014; Meale et al., 2017), and/or ruminal tissue development and absorption capacity (Kong et al., 2016) might be genetically regulated, which could directly or indirectly affect the 'individualized' rumen microbial population.

In summary, most studies converge to show that, although minor, there are significant differences in the rumen microbiome associated with animal variation in feed efficiency. It is not clear, however, whether the differences observed have causal effects on animal-to-animal variation in feed efficiency, or are rather the consequence of shifts in total intake, digesta biomass and rumen retention time, which 
may co-vary with changes in feed efficiency. To determine whether the rumen microbiome really contributes to animalto-animal variation of feed efficiency or only co-varies with it, future efforts on the analysis of the rumen microbiome should include a higher number of animals and higher sampling frequency and representativeness with complementary measures such as physiological measures (rumen volume, passage rate, rumen $\mathrm{pH}$, etc.), eating behaviour information and host genetic information. At present, our understanding of the impact of host physiology and genetics on the rumen microbiome is still a large 'black box'.

\section{Energy metabolism}

Whole body level

Since the last comprehensive reviews by Richardson and Herd (2004) and Herd and Arthur (2009), which suggested reduced maintenance energy requirements for low RFI lines, there is still a scarcity of data on energy expenditure and its underlying components of divergent RFI lines. In beef cattle, evidence is particularly limited as only two studies evaluated heat production from oxygen consumption measurements (Nkrumah et al., 2006; Chaves et al., 2015). Interpretation of experimental results is generally hampered by the fact that major potential underlying mechanisms (e.g. digestibility) are often not simultaneously measured. Moreover, the statistical power of the experimental set up is often limited as regards to the small expected differences in heat production between animals identified as divergent for RFI in performance tests and the low precision of the methods. Despite those limits, evidence is emerging that animals showing higher feed efficiency (low RFI) are not only characterized by lower maintenance energy requirements, but also by higher partial efficiency of metabolizable energy (ME) utilization for growth leading to generally higher metabolic energetic efficiency. Only the most illustrative studies are reported here.

Lower maintenance requirements for ME have been demonstrated in pigs in an elegant study combining measurements of respiratory exchanges and a modelling approach to quantify the components of heat production (fasting, activity, short- and long-term thermic effect of feeding, Barea et al., 2010). A 10\% reduction in maintenance requirements was determined in low RFI piglets even after adjustment for differences in energy retention. These results in pigs support, despite species differences, calculations in beef cattle (e.g. Castro Bulle et al., 2007; even if differences were not significant because of low statistical power), including those obtained in heifers by regression for zero BW change (Lawrence et al., 2012; Fitzsimons et al., 2013), of reduced maintenance ME requirements.

Most novel is the emerging evidence for a higher partial efficiency of ME use for growth. Nkrumah et al. (2006) rigorously measured heat production in phenotypically divergent RFI steers, each fed at two feeding levels above maintenance. Adaptation periods were unequal and sometimes short, but results indicated a considerable numerical, although not statistically significant, reduction in the increment of heat production between two feedings levels in low $v$. high RFI steers, and a significant negative correlation between heat production and partial efficiency of growth. Altogether, these results suggest a higher partial efficiency of ME use for growth in low RFI steers. This increased metabolic efficiency of ME use for growth measured at similar intakes highlights that the latter may be a true determinant of feed efficiency and not a passive result of lower intake. This effect associated with a small (5\%) although significantly higher diet digestibility and a marked reduction $(-24 \%$ to $-28 \%)$ in methane emission, explained the improved energy retention when low-RFI steers were fed similar DM intake as high-RFI (Nkrumah et al., 2006), and suggested changes in the composition of the BW gain. Variation in the partial efficiency of ME use for growth has been a matter of debate (e.g. Castro Bulle et al., 2007). A small meta-analysis conducted here (Supplementary Figure S1), which combined ME intake and retained energy calculated from published results in high- $v$. low-RFI steers (excluding Nkrumah et al., 2006, because of controlled intakes during oxygen consumption measurements), indicated an average marginal efficiency of ME utilization for growth ( $\Delta$ retained energy/ $\Delta \mathrm{ME}$ intake) of $0.33 \pm 0.10$, close to the value of 0.25 calculated from Basarab et al. (2003). This slope differs from the average theoretical $\mathrm{kg}$ value of 0.53 expected for animals, such as those in the current data set, which deposit $7 \%$ to $16 \%$ energy as protein (Geay, 1984). It implies that $\mathrm{kg}$ may vary between RFI divergent animals, with a higher partial efficiency of ME use for growth in low-RFI steers, whether maintenance $M E$ requirements are assumed to be unchanged or reduced.

Whether the two mechanisms of low maintenance ME requirements and improved partial efficiency of ME use for growth are combined or not remains to be determined. Indirect evidence for combined changes was provided by Basarab et al. (2003) after adjusting RFI for differences in composition of body gain. However, the dichotomy between reduced maintenance ME requirements and increased partial efficiency for ME use for growth is largely the result of mathematical conventions, experimental conditions and limited numbers of simultaneous measurements, and does not help in identifying the underlying biological mechanisms. In any case, more efficient (low-RFI) animals do appear to have a lower metabolic rate (i.e. heat production expressed by unit weight and unit time, at similar ME intake) than the feed inefficient (low-RFI) animals which can arise from reduction in maintenance or efficiency of ME use for growth, or both, and that needs to be confirmed in future studies.

The lower metabolic rate of more efficient lines (low RFI) may have multiple origins as each metabolic pathway will impact ATP use and production. At the tissue level, protein mass is important because of the high energy cost of protein metabolism. However, low-RFI steers often have leaner carcasses, so there may be a number of mechanisms that contribute to reducing the energy cost of protein-rich tissues. Reduced fractional protein degradation rate was associated 
with lower ME requirements for maintenance in steers (Castro Bulle et al., 2007). In addition, low-RFI animals showed changes in the distribution of muscle fibre types (hypertrophy of fast-twitch glycolytic fibres (Lefaucheur et al., 2011) and generally had lower oxidative and glycolytic activities in muscles (Gilbert et al., 2007)). These are likely to result in a lower average metabolic rate of muscles. Modifications in the distribution of lean mass can also be involved. Gut and liver contribute $38 \%$ to total energy expenditure in growing cattle, which, if attributed to maintenance, represents on average $60 \%$ of theoretical maintenance ME requirements (Ortigues-Marty et al., 2017). This is supported by a positive genetic correlation between the empty digestive tract weight and RFI (Renand and Krauss, 2002), but other studies failed to show differences in the mass of internal organs between RFI divergent animals as discussed further on in this review.

\section{Cellular level}

Between-animal variation in total energy expenditures by animals of similar biotype and management background may arise from a host of cellular energy-consuming processes, including ion pumping (e.g. $\mathrm{Na}+/ \mathrm{K}+$ ATPase), mitochondrial proton leakage, thyroid hormones, leptin, IGF-1, protein turnover, lipid/protein enzymes or sympathetic activity (Johnson et al., 2003). Of these physiological processes, it has been estimated that mitochondrial proton leakage, ion pumping, and protein turnover each contribute $\approx 20 \%$ to total between-animal variation in basal energy expenditures (Rolfe and Brown, 1997). Mitochondria are responsible for producing over $90 \%$ of cellular ATP from acetyl CoA, which is generated upon digestion and catabolism of carbohydrates, protein and lipid derived from the diet and(or) body reserves. Through oxidative phosphorylation (OXP) involving a series of electron transfers through the electron transport chain (ETC), cellular respiration is coupled with the pumping of protons into the intermembrane space, which drives the synthesis of ATP as protons move back into the matrix via ATP synthase. In brown fat, this protomotive force is dissipated due to the presence of an uncoupling protein (UCP1), thereby generating heat rather than ATP. Inefficiency of OXP can also occur due to electron leakage across the ETC, which then generates reactive oxygen species (ROS; superoxide, $\mathrm{H}_{2} \mathrm{O}_{2}$ ) to cause oxidative stress in the absence of sufficient access to antioxidants (e.g. superoxide dismutase).

Bottje et al. (2002) was the first to demonstrate that differences in mitochondrial function were linked to betweenanimal variation in feed efficiency. In a series of studies, Bottje et al. (2002) found that mitochondria (isolated from multiple tissues) from broilers with efficient (low FCR) phenotypes exhibited a more tightly coupled respiratory chain that was associated with less electron leak and ROS production compared to mitochondria from inefficient (high FCR) broilers. Furthermore, the increase in ROS production of mitochondria from inefficient broilers was associated with lower activities of ETC complex proteins (I to IV) (Bottje and Carstens, 2009). A greater degree of ETC coupling was also found in mitochondria isolated from muscle (Kolath et al., 2006) and liver (Lancaster et al., 2014) from beef cattle with low- than high-RFI phenotypes. Moreover, Sharifabadi et al. (2012) reported that activities of ETC complex proteins were substantially higher in low- $v$. high-RFI lambs. These results indicate that mitochondria from feed-efficient animals have enhanced ETC coupling and generate ATP more efficiently from a given amount of substrate.

In support of these findings, Kong et al. (2016) found that genes coding for several mitochondrial proteins involved in OXP were upregulated in rumen epithelium of low- $v$. highRFI steers. Of notable interest, Kong et al. (2016) also reported that relative mitochondrial genome copy number per cell was $26 \%$ lower in rumen epithelium of low- compared with high-RFI steers. This would indicate that feedefficient steers had a greater rate of transcription of genes associated with OXP from a lesser mitochondrial genome in rumen epithelial tissue. Kelly et al. (2011) examined the expression of genes associated with ETC proteins in muscle of steers with divergent RFI phenotypes, while fed both highgrain and high-forage diets. Differences in expression of complexes I, II and III were not detected between low- and high-RFI steers. However, a greater abundance of cytochrome c oxidase (complex IV) mRNA transcript was detected in low-RFI steers, but only when fed the high-grain diet. Kelly et al. (2011) also reported that UCP3 mRNA levels were 2.2-fold higher in muscle of high-RFI steers, which is consistent with the finding that inefficient broilers had higher mRNA for avian UCP (equivalent to UCP3) compared with feed-efficient broilers (Ojano-Dirain et al., 2007). UCP3 in muscle acts to protect cells from oxidative damage by inducing mild uncoupling of OXP to reduced mitochondrial superoxide production. Thus, increased expression of UCP3 mRNA likely serves to attenuate ROS-mediated oxidative damage generated in mitochondria of less-efficient animals. In pigs divergently selected for $\mathrm{RFI}$, several antioxidant genes/proteins (e.g. superoxide dismutase) were overexpressed in muscle of high-RFI pigs (Vincent et al., 2015), suggesting that several adaptive mechanisms may have evolved to cope with higher rates of ROS production in mitochondria from less feed-efficient animals.

Kelly et al. (2011) found that mRNA transcripts for the coactivator for peroxisome proliferator activated receptor (PGC-1) were 1.7-fold higher in low- compared with high-RFI steers. Increased expression of PGC-1 has been associated with increased mitochondrial biogenesis, enhanced mitochondrial respiration and the induction of several ROSdetoxifying enzymes. The fact that mitochondrial biogenesis may be elevated in low-RFI phenotypes by increased gene expression of PGC-1 appears to run counter to the reduction in mitochondrial content observed in rumen epithelium from low-RFI steers (Kong et al., 2016). Moreover, utilizing both transcriptomic and proteomic approaches, Vincent et al. (2015) presented compelling evidence to show that genes/ proteins associated with mitochondrial oxidative metabolism were downregulated, and that mitochondrial content was reduced in muscle of pigs selected for low RFI. Thus, selection 
for low RFI in pigs appears to have altered both mitochondrial biogenesis as well as intrinsic mitochondrial composition to affect the efficient mitochondrial phenotype. Interestingly, when high-RFI pigs were pair fed to match the intake of low-RFI pigs, differences due to divergent RFI selection were still evident, indicating that the molecular mechanisms associated with variation in mitochondrial energy metabolism were largely independent of differences in voluntary feed intake. The apparent discrepancies noted between some of the abovementioned studies no doubt reflect differences in species, tissue and methodologies, as well as the feed-efficiency phenotype (e.g. FCR v. RFI) used in experimental designs. Continued research that seeks to discover mechanisms controlling mitochondrial function and biogenesis will undoubtedly lead to better understanding of the cellular basis for between-animal variation in efficiency of feed utilization, as well as to the discovery of biomarkers to more accurately identify feed-efficient livestock.

\section{Protein turnover}

Protein turnover can be defined as the continuous process of degradation and synthesis of proteins leading to no net changes in mass but to a renewal. Thus, for growing animals, where protein accretion occurs because protein synthesis is greater than degradation, the protein turnover is equal to total protein degradation or alternatively an equal amount of freshly synthesized protein that replaces degraded protein. This means that in growing animals the protein turnover can be indirectly assessed through the intensity of protein degradation. The protein turnover in growing-fattening young bulls is huge compared with the net protein deposition with as high as $94 \%$ of the whole body protein synthesis only serving to counterbalance the protein degradation (Lobley et al., 2000). This huge turnover is accompanied by a considerable individual genetic variation (Hawkins, 1991; Oddy et al., 1995).

Protein turnover is essential for life, providing the amino acid flux that enable maintenance services such as metabolic regulation, cellular repair and rapid adaptation against environmental changes, among other functions. However, protein turnover represents an apparently futile cycle that entails a high energy cost to the organism. The estimated energy expenditure associated with protein synthesis may account on average $23 \%$ of the total energy expenditure in ruminants (Caton et al., 2000), a figure that agrees with theoretical estimates found in other species. This estimate represents, however, a minimal energy-cost related to total protein turnover since associated energy requirements for amino acid and associated ion transport, RNA turnover, metabolic regulation and protein degradation are not taken into consideration. Fractional protein turnover rate (i.e. protein degradation per unit of protein mass and time; \%/day) is thus commonly regarded as a general index of individual variation in energy requirements for maintenance (Hawkins, 1991), and it has been evoked as a potential determinant of between-animal differences in animal performance (Hawkins, 1991), and RFI (Richardson and Herd, 2004).

From a theoretical point of view, the most economical way of achieving higher growth efficiencies would be by a reduction in the protein degradation rate rather than by an increase in the synthesis rate. However, this is not always observed in the literature. Different relationships are obtained when analysing available data (Supplementary Table S2; Studies\#16 to 32) from metabolic studies carried out in different livestock species in which changes in feed efficiency were measured at the same time as fractional protein degradation rate (assumed here to reflect changes in protein turnover rate for growing animals). Overall, in most of the evaluated studies, efficient individuals seemed to adopt a low protein turnover strategy (Studies \#16 to 25). In contrast, other authors reported that efficient individuals show either no differences in protein fractional degradation rates or a concomitant increase (Supplementary Table S2). Despite its associated energy cost, an increase in protein turnover may be still compatible with higher feed efficiency provided that the proportion of total protein synthesis retained as net protein (i.e. efficiency of retention of synthesized proteins) increases, or in other words as far as protein synthesis increases at a higher extent than protein degradation. These somewhat controversial relationships shown in Supplementary Table \$2 may stem from differences in methods used for measuring protein degradation (isotopic methods $v$. 3-methylhistidine marker $v$. postmortem enzymatic activities), the way to rank animals in terms of extreme feed efficiency phenotypes, the animal species and their stage of maturity. From data shown in Supplementary Table S2 it can be noted in some cases higher feed efficiency was associated with lower intakes (RFI), whereas in other studies lower intake was not observed. Feed intake, and especially protein intake, strongly affect protein turnover in several different ways (Waterlow, 2006), and thus the association between feed efficiency and protein turnover rate should be assessed with caution in relation to concomitant changes in feed intake. Indeed, when efficient genetic lines consuming less feed were compared to unselected lines in poultry a lower protein turnover rate in muscle was reported (Study\#16a in Supplementary Table S2). In contrast, in the same study when selection pressure was for higher growth rates, entailing both a higher feed intake and feed efficiency (lower FCR), no changes in protein turnover compared with unselected lines were observed (Study\#16b). This highlights the importance of the choice of the feed efficiency index when assessing the role of potential biological determinants. This is well illustrated also by results reported within the same study ranking beef cattle through two different feed efficiency indices: protein turnover rate did not correlate with RFI (Study \#27a) but a negative relationship was found with FCR (more efficient cattle showed higher protein turnover; Study \#27b). When looking at the few studies in Supplementary Table $\$ 2$ where feed efficiency was compared at similar DM intake, in an attempt to avoid the confounding effect of intake, results suggest a role of protein turnover rate 
beyond the effect of intake: two out three fish studies (Studies \#17 and 18) found that whole-body protein turnover decreased in high growth-efficient animals, whereas the third did not find statistical differences (Study \#26). In ruminants protein turnover rate has been shown to increase as the level of intake increases (Lobley et al., 2000) but this relationship could be completely inverted in high growthefficiency genetic lines (Studies \#19 and 21). Interestingly and in the same direction, a different protein degradation response to feed intake was observed in healthy human adults classed as efficient $v$. non-efficient in terms of feed protein utilization: the most efficient individuals decreased their protein degradation as feed intake increased to a greater extent than less efficient ones (Fereday et al., 1998). Overall, this could indicate that genetic variation might exist concerning the protein degradation response to feed intake, variations likely driven by hormonal regulation (Oddy et al., 1995).

In conclusion, although there is a scarcity of protein turnover data obtained in beef cattle through isotopic methods in vivo, most of reported studies in livestock species suggest a negative correlation between feed efficiency and protein turnover rate. Long-term studies are warranted in the future to evaluate in beef cattle the role of protein turnover rate on feed efficiency regardless of intake changes (e.g. residual gain).

\section{Body composition}

Nutrient requirement and energetic efficiency of cattle is complex due to differences in relative organ and tissue growth patterns. With increasing age and slaughter weight, the proportions of non-carcass parts, bone and muscle decrease, whereas the proportions of fat in non-carcass, carcass and muscle (marbling) all increase (Moloney and McGee, 2017). Due to the high metabolic cost associated with organs such as the gastro-intestinal tract and liver it is likely that between-animal variation in the size and functionality of these organs may influence energy requirements (Fitzsimons et al., 2017; Meale et al., 2017). Although a positive genetic relationship between RFI and the empty digestive tract was noted in pure Charolais young bulls ( $n=946 ; r_{g}: 0.42$; Renand and Krauss, 2002), the limited published literature that has examined variation in visceral organ size amongst animals of divergent feed efficiency status is inconsistent (Kenny et al., 2018). For example, a number of studies have found that high-RFI cattle have a heavier gastro-intestinal tract, reticulo-rumen, liver, kidneys, bladder and/or heart compared their low-RFI counterparts, whereas other studies have failed to establish an effect of RFI status on the weight of these organs (Fitzsimons et al., 2014; Kenny et al., 2018; Meale et al., 2017).

Differences in the rates of protein and fat deposition influence feed efficiency and rate of BW gain primarily because fat has higher energy density than protein; however, although more ME is required for fat than for protein deposition (wet tissue basis), maintenance of protein requires more ME than maintenance of fat (Moloney and McGee, 2017). Currently, there is inconsistency in the published literature on the body compositional differences between cattle divergent in feed efficiency status (Fitzsimons et al., 2017; Kenny et al., 2018). To evaluate the relationship between RFI status and measures of body composition Kenny et al. (2018) conducted a meta-analysis of phenotypic studies that used growing beef cattle offered energy-dense diets. In relation to muscle accretion, they found no statistically significant differences in either live animal or carcass measures between cattle of high- or low-RFI status. Similarly, they failed to observe a statistically significant difference in ultrasonically measured back fat depth between cattle divergent in RFI. It was concluded that RFI rank in growing cattle was not obviously associated with final muscle area, carcass muscle area and change in back fat depth during the linear phase of the growth curve, typical of RFI test periods in many studies. Similarly, inconsistencies in the literature exist or relationships are absent for associations between RFI in beef cattle and systemic metabolic indicator traits for body composition and those connected with anabolic processes (Kenny et al., 2018); these include, creatinine (negative association, Lawrence et al., 2012; Fitzsimons et al., 2013; no association, Fitzsimons et al., 2014), leptin (no association, Kelly et al., 2010), and IGF-I and insulin (no association, Kelly et al., 2010; Lawrence et al., 2012). Discrepancies amongst literature reports is certainly exacerbated by variation among studies in breed, gender and stage of physiological maturity of the cattle employed, coupled with huge disparity in methodologies used and reporting of results (Kenny et al., 2018). Theoretically, greater effects of body composition (fatness) would be expected in cattle with a relatively lower mature weight, especially when offered a high-energy diet. In addition, discrepancies between studies may be influenced by genotype-by-environment interactions. In contrast, a meta-analysis of genetic correlations between RFI and FCR, and body composition traits in growing beef cattle (Berry and Crowley, 2013) showed that, despite large variability across studies, in general there was a positive association of RFI and FCR with body fat in live animals or carcasses and a general tendency for RFI to be negatively correlated to lean body mass, muscularity and carcass conformation. Given this background, many studies include an adjustment for body fat in the statistical model for computing RFI (e.g. Kelly et al., 2010). This adjustment can increase the $R^{2}$ of the statistical model from less than one to up to 5 percentage units; however, the significance and contribution of body composition per se to the accuracy of the model is not always stated (Kenny et al., 2018).

Nevertheless, due to the well-established influence of body fatness on key reproductive events, such as the onset of puberty and resumption of postpartum ovarian cyclicity (Kenny et al., 2018), female 'robustness', particularly associated with mobilization and deposition of body fat reserves, and potentially meat quality traits, this adjustment is prudent. In the context of beef cattle genetic improvement 
programmes, consideration for potential antagonism among commercially important traits needs to accounted for by using economically weighted, multiple-trait genetic selection indices to identify superior animals (Moloney and McGee, 2017).

In summary, body composition accounts for a relatively small proportion of the between-animal variation in feed efficiency.

\section{Endocrine system}

The endocrine system, an inter-organ communicator, could affect feed efficiency through its role in the regulation of both feed intake and nutrient utilization. Although this appears to be self-evident, most of the experiments looking into the specific role of hormones and neuropeptides in animal-toanimal variations in feed efficiency were not designed to evaluate causality, but rather to assess simple associations.

The gastro-intestinal tract with the attached glands is the first system that senses the diet and its energy, and it secretes hormones that play an important role in regulating both feed intake (i.e. insulin and ghrelin) and nutrient utilization (i.e. glucose-dependent insulinotropic polypeptide, insulin and IGF-1). Diet composition and energy concentration change gut hormone concentrations, regulating ME intake (Relling and Reynolds, 2008) and energy utilization (Relling et al., 2014). For example, the expression of some orexigenic (i.e. appetite stimulant) and anorexigenic (i.e. loss of appetite) neuropeptides such as neuropeptide $Y$ or proopiomelanocortin, respectively, differs between high and low RFI animals (Perkins et al., 2014), but unfortunately the experimental design hampers any conclusion beyond a simple association.

Ghrelin concentration has been associated with energy intake/partitioning in ruminants (Jennings et al., 2011). However, current data does not discern whether ghrelin is a true regulator of DM intake. Foote et al. (2014) showed an association between plasma total ghrelin concentration and FCR. However, this was dependent on the time when plasma was sampled in relation to the feeding process, because this association was not found in studies with multiple samplings (Foote et al., 2016). Moreover, if ghrelin affects feed intake and animal growth, it may depend on the physiological state and type of diet (Jennings et al., 2011; Foote et al., 2014). The role of glucose-dependent insulinotropic polypeptide on beef cattle has not been studied in detail with no available data evaluating its role on feed efficiency. However, in dairy cows a positive association was found between plasma glucose-dependent insulinotropic polypeptide and milk energy output when data were corrected for ME intake (Relling et al., 2014).

Specific hormones related to nutrient metabolism may have a role in between-animal variation in feed efficiency, especially hormones involved in the somatorophic axis (composed by growth hormone, IGFs and their binding proteins), leptin and cortisol. IGF-1 has been proposed as a biomarker of RFI by some authors because of its stimulation of protein synthesis (Davis et al., 2012), and the fact that protein turnover is one of the main determinants of feed efficiency evoked in the present review. However, given the potential confounding factors, IGF-1 concentration are not always associated with variations in RFI (Supplementary Table S3). Important potential factors responsible for equivocal results could be the differences in diets or in physiological stages of the animals and interactions between the somatorophic axis and other hormones and metabolic pathways. Indeed, IGF-1 has been negatively associated with RFI in most of the studies using low-concentrate or lowenergy diets (as described in Supplementary Table S3; Studies \#28, 29, 30, 32a, 33a). In contrast, on high-concentrate diets, the response is not always consistent. In some studies there is no association between IGF and RFI, whereas in others it is negative (Supplementary Table S3; Studies \#31, $32 \mathrm{~b}$ and 35 ) or dependent on the time of sampling (Supplementary Table S3, Study \#34). Another hormone whose function has been associated with feed efficiency is leptin. The association of leptin and feed efficiency is inconsistent as well (Supplementary Table S3). For example, while in some studies there is no association between leptin and RFI (Supplementary Table S3; Studies \#30, 36a, 40) in others there was either negative (Supplementary Table S3; Study \#41) or positive (Table S3; Studies \#36b, 37, 38, 39) association. In contrast to the IGF-1 results, literature results do not indicate a different leptin response according to the diet. However, it has been shown within the same studies (Supplementary Table S3, Study \#36a,b and 39) that the association of leptin and RFI or FCR depends on the physiological stage of the animal. When leptin was measured in young animals, there was no association with RFI, whereas an association was noted when the analysis was conducted near the end of a fattening period. Multiple sampling during the growing and finishing period will help to remove some of the confounded effects and allow a greater understanding of the role of the hormones on efficiency (Supplementary Table S3, Study \#39). Finally, cortisol has been also proposed as a marker of RFI because of its role in increasing protein turnover (Davis et al., 2012). As for IGF-1 and leptin, the association is not always present (Supplementary Table S3). This difference could be attributed to multiple factors, such as stress or sampling time in relation with the circadian cycle of the animal. For example within the same study (Supplementary Table S3, Studies $\# 36 \mathrm{c}$ and $36 \mathrm{~d}$ ), there was an association between cortisol and RFI at the end of the animal house confinement (more stress), whereas it was absent at the end of the feedlot period (less stress). Furthermore, while there were no differences when samples are taken in a daily basis, significant associations between RFI and cortisol were found at specific times (evening) when multiple samples were obtained within the same day (Supplementary Table S3, Studies \#41a and $41 \mathrm{~b}$ ).

As mentioned earlier, there are many partial and contradictory data on the association of plasma hormone concentrations and feed efficiency in beef cattle (RFI and FCR). 
Many of the apparent contradictions are due to interactions among plasma hormone concentrations, diet, physiological stage, age of the animals or even the specific sampling time. With the available data and experimental designs it is impossible to conclude that the improvements of RFI or FCR are hormone-driven. In addition, since feed efficiency changes are unavoidably associated with changes in feed (energy) intake when it is measured as RFI (and to a lesser extent to FCR) it is impossible to disentangle the true cause and effect relationships.

\section{Molecular basis of animal-to-animal variation in feed efficiency}

As with other complex traits (also referred to as quantitative or polygenic traits), feed efficiency is controlled by many genes which are involved in several molecular mechanisms and pathways causing animal-to-animal genetic variation in different biological functions.

Although traits such as RFI are usually determined to be phenotypically independent of growth and body size, as well as fatness when phenotypes are adjusted for fat, this is not the case from a genetic standpoint as revealed by genomic analysis (Saatchi et al., 2014; Ceacero et al., 2016). This is perhaps to be anticipated as analysis of genetic parameters reveal correlations between these traits (e.g. $r_{g}$ ranged from 0.22 to 0.71; Ceacero et al., 2016) and it is expected that some genes would have a pleiotropic effect on these traits (Saatchi et al., 2014) and are involved in complex gene networks (see Supplementary Figure S2). This adds another level of complexity to the understanding of biological mechanisms contributing to animal-to-animal variation in feed efficiency and may result in co-selection for other traits when selection is applied for feed efficiency. Nonetheless, recent advances in Omics approaches, sequencing, genotyping, statistical methods and bioinformatics tools have led to new information on the molecular basis of feed efficiency traits.

For this review, and after a detailed analysis of genes, proteins and metabolites associated with RFI (summarized in Supplementary Materials SM1 to SM3 and Supplementary Table S4), we conducted an overall gene interaction network analysis using Ingenuity Pathway Analysis (IPA; Ingenuity Systems, www.ingenuity.com) of the various results described in Supplementary Table S4. Only the most recent and representative studies at each functional level (genes, RNA, proteins and metabolites) are here analysed. In total, 334 genes, proteins and metabolites were identified from literature and used in IPA. Approximately 24 networks and their linked functions involved in the molecular basis of feed efficiency were obtained (see Supplementary Table S5). Combining these networks identified five main biological functions involved in feed efficiency (summarized in Supplementary Figure S2): (1) growth and proliferation, cell cycle and carbohydrate metabolism, (2) energy production and lipid metabolism, (3) cell signalling and transport, (4) organ development and cell and organ morphology, (5) cancer, organismal injury and abnormalities and disease (i.e. genes, proteins, and metabolites involved in inflammation, immunity, disease as well as oxidative stress). These gene interaction networks and their linked functions are in agreement with the general biological mechanisms proposed by Richardson and Herd (2004). Nonetheless, they provide more detail about each mechanism as well as the interaction among these mechanisms. For example, the energy production and lipid metabolism networks showed connection between important genes such as ACSL6, UCP2, Peroxisome Proliferator-Activated Receptor Gamma, Coactivator 1 Alpha, and mechanistic target of rapamycin complex 1 (Supplementary Figure S2c). Peroxisome Proliferator-Activated Receptor Gamma, Coactivator 1 Alpha is a key transcriptional coactivator that regulates genes involved in adipogenesis, muscle fibre type determination and mitochondrial biogenesis. The mechanistic target of rapamycin gene is involved in protein synthesis regulated by growth hormone receptor and thyroid-stimulating hormone. Thus, selection for RFI could optimize energy production as well as lipid and protein metabolism.

The results from pathway analyses using Database for Annotation, Visualization and Integrated Discovery v6.8 (Supplementary Table S6) provided several enriched biological pathways and their corresponding genes associated with feed efficiency (Figure 3). Based on the number of genes involved in these pathways, phosphatidylinositol-4,5bisphosphate 3-kinase and protein kinase B singnalling pathway (PI3K-Akt), mitogen-activated protein kinases (MAPK) and rat sarcome proteins related to signal transduction pathways (Ras) signalling pathways, involved in protein synthesis, cellular growth and proliferation and apoptosis are very important in understanding the molecular basis of feed efficiency. Nonetheless, a study to calculate the variance explained by each and together in total for these pathways is required.

\section{Implications for knowledge of molecular pathways and biomarkers}

The physiological determinants of feed efficiency or putative biomarkers could be used as a cost-effective and rapid tool for genetic selection or management decisions. Blood (plasma) concentrations of IGF-I, $\beta$-hydroxybutyrate, leptin and glucocorticoids (e.g. cortisol) might be indicators for feed efficiency, although no marker has successfully explained enough of the variability in RFI that they were used as part of routine improvement program (Huang et al., 2006). Other putative biomarkers such as creatine, hipurate and carnitine were proposed to be used as a selection tool for feed efficiency (Karisa et al., 2014). Furthermore, using putative causative mutations in genes associated with feed efficiency in a customized genetic marker panel may improve breeding value prediction and result in more consistent prediction across breeds and management groups. It is anticipated that 


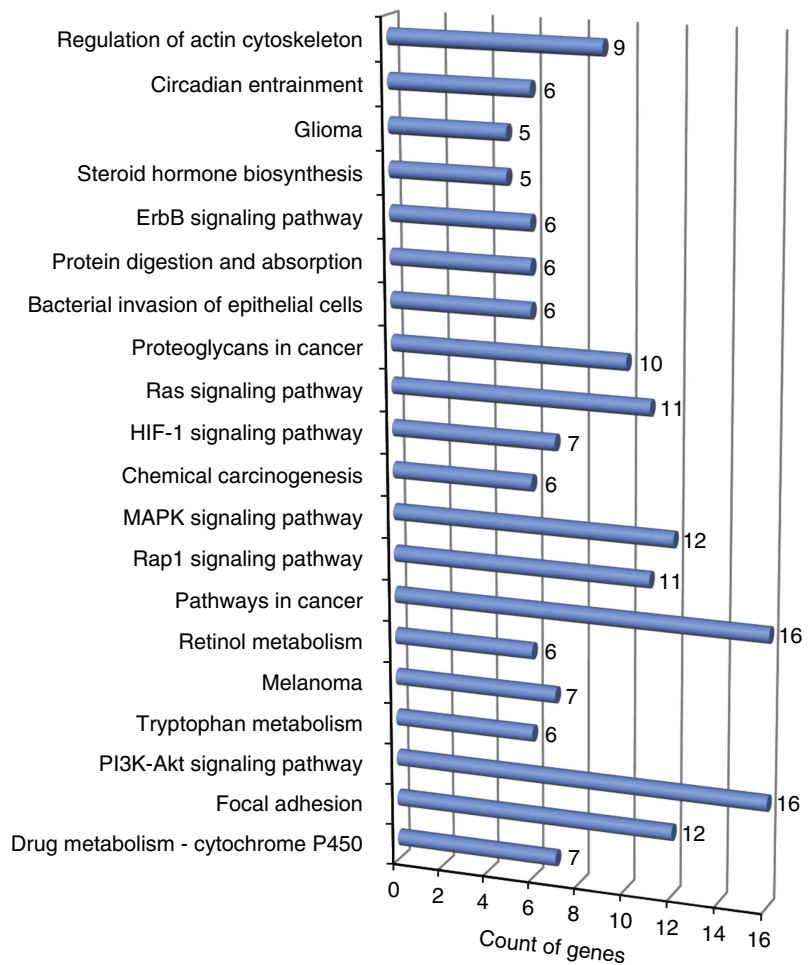

Figure 3 Enriched $(P<0.05)$ biological pathway linked to the discussed gene list associated with feed efficiency in beef cattle. ErbB is the epidermal growth factor family of receptor tyrosine kinases, Ras is the rat sarcome proteins related to signal transduction pathways, MAPK is the mitogen-activated protein kinases, Rap1 is a Ras-related protein 1, PI3KAkt is the phosphatidylinositol-4,5-bisphosphate 3-kinase and protein kinase B singnaling pathway, and HIF-1 is an hypoxia inducible factor protein (colour online).

the continued development of such markers will result in a cost-effective genomic tool to select efficient and productive crossbred animals in the near future.

Selection for efficient animals for optimal processes (activation or inhibition) of different biological or physiological functions will be possible. However, other traits including growth, meat quality, fertility, life-time productivity and robustness as well as behavioural traits can be affected with different magnitude and direction when selecting for feed efficiency. These effects may result from genes with pleiotropic effects or from linkage between genes. For example, genetic correlations were found between RFI and subcutaneous fat thickness $(r=0.37)$ and rump fat thickness $(r=0.32)$ even after accounting for these traits in the model (Ceacero et al., 2016). This may be explained by the downregulation of genes involved in fat deposition in adipose and muscle tissue in efficient animals (Weber et al., 2016). Body fatness and actual body composition play critical roles in male and female fertility traits. As a result efficient bulls had delayed sexual maturity as a strong relationship exists between the onset of puberty and RFI in cattle even after adjustment for body composition (Huang et al., 2006). Although selection of efficient animals based on FCR was not found to affect female fertility traits, selection of efficient animals based on RFI had an unfavourable effect on days to calving (Mu et al., 2016). Genes involved in the MAPK signalling pathway and linked to tissue development especially ossification and adipose tissue were found to have pleotropic effects on calving ease and birth weight (Saatchi et al., 2014). Regulating protein degradation through the gene networks linked to growth and proliferation may explain the association between RFI and carcass and meat quality traits including tenderness but also a possible trade-off between feed efficiency (which benefits from low-protein turnover) and adaptability and robustness (which benefits from highprotein turnover) of animals (Rauw et al., 1998). In conclusion, selecting efficient animals may result in genetic change in growth, decrease in feed intake, subcutaneous fat thickness, delayed sexual maturity as well as lean meat and lower animal robustness. Incorporating these traits or their putative biomarkers within a selection index should avoid these potential negative effects to result in desired improvement in efficiency and other important economic traits.

\section{Conclusions}

As anticipated, the number of potential mechanisms involved in animal-to-animal variation in feed efficiency is huge and inter-connected. However, several conclusions can be drawn from this review. First, feeding and digestive-related mechanisms (i.e. feeding behaviour, digestion, methane emission and rumen microbiome) seem to be associated with RFI mainly because they co-vary with DM intake. Their role as true determinants of animal variability in feed efficiency could be minor. However, this should be confirmed in future experiments by (i) controlling DM intake in the analysis of biological determinants (e.g. animal ranking based on residual gain), (ii) combining different physiological measures in the same study and (iii) testing the relationship in grazing conditions or with high-forage diets. Concerning the metabolic-related mechanisms, despite the scarcity of studies using reference methods it seems that efficient (low-RFI) animals have a significantly lower energy metabolic rate regardless of the associated intake reduction. Energy metabolism could thus be a true determinant of animal-to-animal variation in feed efficiency. The lower heat production (from maintenance and production) in efficient (low-RFI) animals may stem from both a decreased protein turnover and a higher efficiency of ATP production in mitochondria, as both mechanisms were also identified in the molecular network analysis conducted in the present review. In contrast, hormones and body composition could not be conclusively related to animal-to-animal variation in feed efficiency. The analysis of potential biological networks underlying RFI variations highlighted other significant pathways such as lipid metabolism and immunity and stress response. The relevance of these pathways should be confirmed in further studies combining information gathered at different molecular levels (genes, RNA, protein and metabolites). Finally, emerging knowledge suggests that metabolic functions underlying 
genetic variation in feed efficiency (protein turnover, lipid metabolism, immunity) could be associated with other important traits in animal production. This emphasizes the relevance of understanding the biological basis of relevant animal traits to better define future balanced breeding programmes.

\section{Supplementary materials}

To view supplementary material for this article, please visit https://doi.org/10.1017/S1751731118001489

\section{Acknowledgements}

The authors would like to thank Dr Zhou and Dr Morgavi for their advices on the rumen microbiota section. G.C.-H. thanks the scientific committee of the 10th International Symposium on the Nutrition of Herbivores for proposing him to make this review.

\section{Declaration of interest \\ Authors declare no conflicts of interest.}

\section{Ethics statement}

Not applicable.

\section{Software and data repository resources Not applicable.}

\section{References}

Allen MS 2014. Drives and limits to feed intake in ruminants. Animal Production Science 54, 1513-1524.

Archer JA, Richardson EC, Herd RM and Arthur PF 1999. Potential for selection to improve efficiency of feed use in beef cattle: a review. Australian Journal of Agricultural Research 50, 147-162.

Arthur PF and Herd RM 2012. Genetic improvement of feed efficiency. In Feed efficiency in the beef industry (ed. RA Hill), pp. 93-103. Wiley-Blackwell, Ames, IA, USA.

Barea R, Dubois S, Gilbert H, Sellier P, Van Milgen J and Noblet J 2010. Energy utilization in pigs selected for high and low residual feed intake. Journal of Animal Science 88, 2062-2072.

Basarab JA, Beauchemin KA, Baron VS, Ominski KH, Guan LL, Miller SP and Crowley JJ 2013. Reducing GHG emissions through genetic improvement for feed efficiency: effects on economically important traits and enteric methane production. Animal 7, 303-315.

Basarab JA, Price MA, Aalhus JL, Okine EK, Snelling WM and Lyle KL 2003. Residual feed intake and body composition in young growing cattle. Canadian Journal of Animal Science 83, 189-204.

Berry DP and Crowley JJ 2013. Cell biology symposium: genetics of feed efficiency in dairy and beef cattle. Journal of Animal Science 91, 1594-1613.

Bonilha SFM, Branco RH, Mercadante MEZ, Cyrillo JNDS, Monteiro FM and Ribeiro EG 2017. Digestion and metabolism of low and high residual feed intake Nellore bulls. Tropical Animal Health and Production 49, 529-535.

Bottje WG and Carstens GE 2009. Association of mitochondrial function and feed efficiency in poultry and livestock species. Journal of Animal Science 87, E48-63E.

Bottje WG, Tang ZX, Iqbal M, Cawthon D, Okimoto R, Wing T and Cooper M 2002. Association of mitochondrial function with feed efficiency within a single genetic line of male broilers. Poultry Science 81, 546-555.

Castro Bulle FCP, Paulino PV, Sanches AC and Sainz RD 2007. Growth, carcass quality, and protein and energy metabolism in beef cattle with different growth potentials and residual feed intakes. Journal of Animal Science 85, 928-936.

Caton JS, Bauer ML and Hidari H 2000. Metabolic components of energy expenditure in growing beef cattle - review. Asian-Australasian Journal of Animal Science 13, 702-710.

Ceacero TM, Mercadante MEZ, Cyrillo JNDSG, Canesin RC, Bonhila SFM and de Albuquerque LG 2016. Phenotypic and genetic correlations of feed efficiency traits with growth and carcass traits in Nellore cattle selected for postweaning weight. PLoS One 11, e0161366.

Coyle S, Fitzsimons C, Kenny DA, Kelly AK and McGee M 2016. Repeatability of feed efficiency in beef cattle offered grass silage and zero-grazed grass, Journal of Animal Science 94, 719 (Abstract).

Coyle S, Fitzsimons C, Kenny DA, Kelly AK and McGee M 2017. Feed efficiency correlations in beef cattle offered zero-grazed grass and a high-concentrate diet. Advances in Animal Biosciences 8, 121.

Chaves AS, Nascimento ML, Tullio RR, Rosa AN, Alencar MM and Lanna DP 2015. Relationship of efficiency indices with performance, heart rate, oxygen consumption, blood parameters, and estimated heat production in Nellore steers. Journal of Animal Science 93, 5036-5046.

Davis ME, Wick MP and Maquivar MG 2012. Hormonal regulation of feed efficiency. In Feed efficiency in the beef industry (ed. RA Hill), pp. 175-198. WileyBlackwell, Ames, IA, USA.

Donoghue KA, Bird-Gardiner TL, Arthur PF, Herd RM and Hegarty RS 2015. Genetic parameters for methane production and relationships with production traits in Australian beef cattle. Association for the Advancement of Animal Breeding and Genetics 21, 114-117.

Donoghue KA, Bird-Gardiner T, Arthur PF, Herd RM and Hegarty RS 2016. Genetic and phenotypic variance and covariance components for methane emission and postweaning traits in Angus cattle. Journal of Animal Science 94, 1438-1445.

Fereday A, Gibson NR, Malcolm COX and Millward DJ 1998. Variation in the apparent sensitivity of the insulin-mediated inhibition of proteolysis to amino acid supply determines the efficiency of protein utilization. Clinical Science 95, 725-733.

Fitzsimons C, Kenny DA, Fahey AG and McGee M 2013. Methane emissions, body composition and rumen fermentation traits of beef heifers differing in phenotypic residual feed intake. Journal of Animal Science 91, 5789-5800.

Fitzsimons C, Kenny DA and McGee M 2014. Visceral organ weights, digestion and carcass characteristics of beef bulls differing in residual feed intake offered a high concentrate diet. Animal 8, 949-959.

Fitzsimons C, McGee M, Keogh K, Waters SM and Kenny DA 2017. Molecular physiology of feed efficiency in beef cattle. In Biology of domestic animals (ed. CG Scanes and RA Hill), pp. 120-163. CRC Press, FL, Boca Raton, USA.

Foote AP, Hales KE, Lents CA and Freetly HC 2014. Association of circulating active and total ghrelin concentrations with dry matter intake, growth, and carcass characteristics of finishing beef cattle. Journal of Animal Science 92, 5651-5658. Foote AP, Tait RG Jr, Keisler DH, Hales KE and Freetly HC 2016. Leptin concentrations in finishing beef steers and heifers and their association with dry matter intake, average daily gain, feed efficiency, and body composition. Domestic Animal Endocrinology 55, 136-141.

Freetly HC, Lindholm-Perry AK, Hales KE, Brown-Brandl TM, Kim M, Myer PR and Wells JE 2015. Methane production and methanogen levels in steers that differ in residual gain. Journal of Animal Science 93, 2375-2381.

Geay $Y$ 1984. Energy and protein utilization in growing cattle. Journal of Animal Science 58, 766-778.

Gilbert H, Bidanel JP, Gruand J, Caritez JC, Billon Y, Guillouet P, Lagant H, Noblet $J$ and Sellier $P$ 2007. Genetic parameters for residual feed intake in growing pigs, with emphasis on genetic relationships with carcass and meat quality traits. Journal of Animal Science 85, 3182-3188.

Gregorini P, Gunter SA, Beck PA, Soder KJ and Tamminga S 2008. Review: the interaction of diurnal grazing pattern, ruminal metabolism, nutrient supply, and management in cattle. Professional Animal Scientist 24, 308-318.

Goopy JP, Donaldson A, Hegarty R, Vercoe PE, Haynes F, Barnett M and Oddy VH 2014. Low-methane yield sheep have smaller rumens and shorter rumen retention time. British Journal of Nutrition 111, 578-585.

Guan L., Nkrumah JD, Basarab JA and Moore SS 2008. Linkage of microbial ecology to phenotype: correlation of rumen microbial ecology to cattle's feed efficiency. FEMS Microbiology Letters 288, 85-91. 
Hawkins AJS 1991. Protein turnover: a functional appraisal. Functional Ecology 5, 222-233.

Herd RM and Arthur PF 2009. Physiological basis for residual feed intake. Journal of Animal Science 87, E64-E71.

Herd RM, Arthur PF, Donoghue KA, Bird SH, Bird-Gardiner T and Hegarty RS 2014. Measures of methane production and their phenotypic relationships with dry matter intake, growth, and body composition traits in beef cattle. Journal of Animal Science 92, 5267-5274.

Herd RM, Oddy VH and Richardson EC 2004. Biological basis for variation in residual feed intake in beef cattle. 1. Review of potential mechanisms. Australian Journal of Experimental Agriculture 44, 423-430.

Herd RM, Velazco Jl, Arthur PF and Hegarty RF 2016. Associations among methane emission traits measured in the feedlot and in respiration chambers in Angus cattle bred to vary in feed efficiency. Journal of Animal Science 94, 4882-4891.

Hernandez-Sanabria E, Goonewardene LA, Li M, Mujibi DF, Stothard P, Moore SS and Leon-Quintero MC 2010. Correlation of particular bacterial PCRdenaturing gradient gel electrophoresis patterns with bovine ruminal fermentation parameters and feed efficiency traits. Applied and Environmental Microbiology 76, 6338-6350.

Huang W, Hines $\mathrm{H}$ and Davis M 2006. Estimation of genetic trend in IGF-I concentration and correlated response in growth traits in lines of Angus beef cattle divergently selected for serum IGF-I concentration. Journal of Animal Science 84, 109-110.

Jami E and Mizrahi I 2012. Composition and similarity of bovine rumen microbiota across individual animals. PloS One 7, e33306.

Jennings JS, Wertz-Lutz AE, Pritchard RH, Weaver AD, Keisler DH and Bruns K 2011. Circulating ghrelin and leptin concentrations and growth hormone secretagogue receptor abundance in liver, muscle, and adipose tissue of beef cattle exhibiting differences in composition of gain. Journal of Animal Science 89, 3954-3972.

Johnson DE, Ferrell CL and Jenkins TG 2003. The history of energetic efficiency research: Where have we been and where are we going? Journal of Animal Science 81, E27-E38.

Jones FM, Phillips FA, Naylor T and Mercer NB 2011. Methane emissions from grazing Angus beef cows selected for divergent residual feed intake. Animal Feed Science and Technology 166, 302-307.

Karisa BK, Thomson J, Wang Z, Li C, Montanholi YR, Miller SP, Moore SS and Plastow GS 2014. Plasma metabolites associated with residual feed intake and other productivity performance traits in beef cattle. Livestock Science 165, 200-211.

Kelly AK, McGee M, Crews DH, Fahey AG, Wylie AR and Kenny DA 2010. Effect of divergence in residual feed intake on feeding behavior, blood metabolic variables, and body composition traits in growing beef heifers. Journal of Animal Science 88, 109-123.

Kelly AK, Waters SM, McGee M, Fonseca RG, Carberry C and Kenny DA 2011. mRNA expression of genes regulating oxidative phosphorylation in the muscle of beef cattle divergently ranked on residual feed intake. Physiological Genomics $43,12-23$.

Kenny DA, Fitzsimons C, Waters SM and McGee M 2018. Invited review: improving feed efficiency of beef cattle: current state of the art and future challenges. Animal, https://10.1017/S1751731118000976.

Kolath WH, Kerley MS, Golden JW and Keisler DH 2006. The relationship between mitochondrial function and residual feed intake in Angus steers. Journal of Animal Science 84, 861-865.

Kong RSG, Guanxiang L, Chen Y, Stothard P and Guan LL 2016. Transcriptome profiling of the rumen epithelium of beef cattle differing in residual feed intake. BMC Genomics 12, 592.

Lancaster PA, Carstens GE, Michal JJ, Brennan KM, Johnson KA and Davis ME 2014. Relationships between residual feed intake and hepatic mitochondrial function in growing beef cattle. Journal of Animal Science 92, 3134-3141.

Lawrence P, Kenny DA, Earley B and McGee M 2012. Grazed grass herbage intake and performance of beef heifers with predetermined phenotypic residual feed intake classification. Animal 6, 1648-1661.

Lefaucheur L, Lebret B, Ecolan P, Louveau I, Damon M, Prunier A, Billon Y, Sellier $P$ and Gilbert $H$ 2011. Muscle characteristics and meat quality traits are affected by divergent selection on residual feed intake in pigs. Journal of Animal Science 89, 996-1010.
Li F 2017. Rumen microbiome associated with feed efficiency and host genetics in beef cattle. PhD thesis, University of Alberta, Edmonton, AB, Canada.

Lobley GE, Sinclair KD, Grant CM, Miller L, Mantle D, Calder AG, Warkup CC and Maltin CA 2000. The effects of breed and level of nutrition on whole-body and muscle protein metabolism in pure-bred Aberdeen Angus and Charolais beef steers. British Journal of Nutrition 84, 275-284.

Manafiazar G, Basarab JA, Baron VS, McKeown L, Doce RR, Swift M, Undi M, Wittenberg $\mathrm{K}$ and Ominskik K 2015. Effect of post-weaning residual feed intake classification on grazed grass intake and performance in pregnant beef heifers. Canadian Journal of Animal Science 95, 369-381.

Meale SJ, Morgavi DP, Cassar-Malek I, Andueza D, Ortigues-Marty I, Robins RJ, Schiphorst AM, Laverroux S, Graulet B, Boudra H and Cantalapiedra-Hijar G 2017. Exploration of biological markers of feed efficiency in young bulls. Journal of Agricultural and Food Chemistry 65, 9817-9827.

Moloney AP and McGee M 2017. Factors influencing the growth of meat animals. In Lawrie's Meat Science, 8th edition (ed. F Toldrá), pp. 19-47. Elsevier Woodhead Publishing, Cambridge, UK.

Mu Y, Vander Voort G, Abo-Ismail M, Ventura M, Jamrozik J and Miller SP 2016. Genetic correlations between female fertility and postweaning growth and feed efficiency traits in multibreed beef cattle. Canadian Journal of Animal Science 96, 448-455.

Nkrumah JD, Okine EK, Mathison GW, Schmid K, Li C, Basarab JA, Price MA, Wang Z and Moore SS 2006. Relationships of feedlot feed efficiency, performance, and feeding behavior with metabolic rate, methane production, and energy partitioning in beef cattle. Journal of Animal Science 84, 145-153.

Oddy VH, Spec PA, Warren HM and Wynn PC 1995. Protein metabolism in lambs from lines divergently selected for weaning weight. The Journal of Agricultural Science 124, 129-137.

Ojano-Dirain C, Toyomizu M, Wing T, Cooper M and Bottje WG 2007. Gene expression in breast muscle and duodenum from low and high feed efficient broilers. Poultry Science 86, 372-381.

Oliveira LF, Ruggieri AC, Branco RH, Cota O, Canesin RC, Costa HJU and Mercadante MEZ 2016. Feed efficiency and enteric methane production of Nellore cattle in the feedlot and on pasture. Animal Production Science 58, 886-893.

Ortigues-Marty I, Cantalapiedra-Hijar G, Vernet J and Nozière P 2017. De l'énergie de la ration à l'utilisation des nutriments chez les ruminants: quel rôle pour les tissus splanchniques? Cahiers de Nutrition et de Diététique 52, 45-53.

Perkins SD, Key CN, Garrett CF, Foradori CD, Bratcher CL, Kriese-Anderson LA and Brandebourg TD 2014. Residual feed intake studies in Angus-sired cattle reveal a potential role for hypothalamic gene expression in regulating feed efficiency. Journal of Animal Science 92, 549-560.

Pope PB, Smith W, Denman SE, Tringe SG, Barry K, Hugenholtz P, McSweeney CS, McHardy AC and Morrison M 2011. Isolation of Succinivibrionaceae implicated in low methane emissions from Tammar wallabies. Science 333, 646-648.

Rauw WM, Kanis E, Noordhuizen-Stassen EN and Grommers FJ 1998. Undesirable side effects of selection for high production efficiency in farm animals: a review. Livestock Production Science 56, 15-33.

Relling AE, Crompton LA, Loerch SC and Reynolds CK 2014. Short communication: plasma concentration of glucose-dependent insulinotropic polypeptide may regulate milk energy production in lactating dairy cows. Journal of Dairy Science 97, 2440-2443.

Relling AE and Reynolds CK 2008. Abomasal infusion of casein, starch and soybean oil differentially affect plasma concentrations of gut peptides and feed intake in lactating dairy cows. Domestic Animal Endocrinology 35, 35-45.

Renand G and Krauss D 2002. Genetic relationship between fattening and slaughter traits in pure bred Charolais young bulls. In Proceedings of the 7th World Congress on Genetics Applied to Livestock Production, 19-23 August, Montpellier, France, Communication 10-08.

Richardson EC and Herd RM 2004. Biological basis for variation in residual feed intake in beef cattle. 2. Synthesis of results following divergent selection. Australian Journal of Experimental Agriculture 44, 431-440.

Richardson EC, Herd RM, Archer JA and Arthur PF 2004. Metabolic differences in Angus steers divergently selected for residual feed intake. Australian Journal of Experimental Agriculture 44, 441-452. 
Rius AG, Kittelmann S, Macdonald KA, Waghorn GC, Janssen PH and Sikkema E 2012. Nitrogen metabolism and rumen microbial enumeration in lactating cows with divergent residual feed intake fed high-digestibility pasture. Journal of Dairy Science 95, 5024-5034.

Rolfe DFS and Brown GC 1997. Cellular energy utilization and molecular origin of standard metabolic rate in mammals. Physiological Reviews 77, 731-758.

Saatchi M, Schnabel RD, Taylor JF and Garrick DJ 2014. Large-effect pleiotropic or closely linked QTL segregate within and across ten US cattle breeds. BMC Genomics 15, 442.

Sauvant $D$ and Nozière $P$ 2016. Quantification of the main digestive processes in ruminants: the equations involved in the renewed energy and protein feed evaluation systems. Animal 10, 755-770.

Sharifabadi HR, Zamiri MJ, Rowghani E and Bottje WB 2012. Relationship between the activity of mitochondrial respiration chain complexes and feed efficiency in fat-tailed Ghezel lambs. Journal of Animal Science 90, 1807-1815.

Vincent A, Louveau I, Gondret F, Tréfeu C, Gilbert H and Lefaucheur L 2015. Divergent selection for residual feed intake affects the transcriptomic and proteomic profiles of pig skeletal muscle. Journal of Animal Science 93, 2745-2758.

Waterlow JC 2006. Protein turnover. CABI Publishing, Wallingford, Oxfordshire, UK.

Weber KL, Welly BT, Van Eenennaam AL, Young $A E$, Porto-Neto $L R$, Reverter $A$ and Rincon $G$ 2016. Identification of gene networks for residual feed intake in Angus cattle using genomic prediction and RNA-seq. PloS One 11, e0152274.

Zetouni L, Henryon M, Kargo M and Lassen J 2017. Direct multitrait selection realizes the highest genetic response for ratio traits. Journal of Animal Science 95, 1921-1925. 